\title{
Esquistossomose mansônica simulando neoplasia da bexiga
}

\author{
Schistosomiasis mansoni simulating bladder neoplasia
}

\author{
Eduardo José Andrade Lopes ${ }^{1}$, Tarsila Carvalho dos Santos ${ }^{2}$ \\ e Vilson Martins ${ }^{3}$
}

\begin{abstract}
RESUMO
Paciente de 36 anos de idade, proveniente de zona endêmica foi admitido com episódios de hematúria macroscópica total e disúria terminal. A citoscopia mostrou um tumor exofítico na parede anterior da bexiga, sugestivo de câncer. A biópsia revelou esquistossomose mansônica. Ressecção transuretral confirmou o diagnóstico. O paciente foi clinicamente tratado com oxamniquine, obtendo cura. O caso apresentado nesse trabalho enfatiza que nem todos os tumores de bexiga com hematúria microscópica são cânceres de bexiga.
\end{abstract}

Palavras-chaves: Esquistossomose mansônica. Tumor vesical. Hematúria. Disúria.

\begin{abstract}
A 36-year-old patient, proceeding from an endemic area was admitted with episodes of total microscopic hematuria and terminal dysuria. Cytoscopy showed a protuberant tumor in the bladder anterior wall, suggestive of cancer. Biopsy revealed schistosomiasis mansoni. Transurethral resection confirmed the diagnosis. The patient was clinically treated and cured with oxamniquine. The case presented in this work emphasizes that not all the tumors of bladder with microscopic hematuria are bladder cancers.
\end{abstract}

Key-words: Schistosomiasis mansoni. Vesical tumor. Hematuria. Dysuria.

Ainda que a esquistossomose mansônica seja endêmica em nosso meio, ela raramente acomete o trato urinário.

A forma vesical da esquistossomose mansônica tem sido descrita como excepcional, sem determinação de sintomas clínicos e tem sido raramente encontrada em necropsias ${ }^{2}$. Em oposição a esse fato, os autores vêm relatar um caso de esquistossomose mansônica, simulando um tumor vesical.

\section{RELATO DE CASO}

Paciente GPLF, masculino, 36 anos de idade, procedente da Cidade de Irará, na Bahia, foi admitido para avaliação depois de apresentar um episódio de hematúria macroscópica total associada a uma disúria terminal. Um processo expansivo projetado para a luz vesical, na parede anterior do órgão, foi acusado em uma ultra-sonografia vesical (Figura 1), sugerindo uma neoplasia vesical. A citoscopia revelou a presença de tumor exofítico situado na parede anterior da bexiga, recoberto por coágulos, sendo portanto muito sugestivo de neoplasia. Uma biópsia da lesão foi feita e esquistossomose mansônica foi diagnosticada por exame anatomopatológico (Figura 2). Foram realizados cinco exames parasitológicos de fezes, tendo todos revelado ovos viáveis de $S$. mansoni, e uma reação intradérmica, fortemente positiva. Foi realizado a ressecção transuretral profunda da lesão que confirmou a presença de granulomas esquistossomóticos com ovos viáveis de $S$. mansoni (Figura 3).

0 paciente foi posteriormente tratado com oxamniquine. Citoscopias feitas depois de 30 e 90 dias mostraram membrana mucosa vesical sem alterações. Ultra-sonografia e parasitológicos de fezes foram realizados a cada 3 meses seguintes e os resultados foram normais. 0 paciente prossegue assintomático.

\footnotetext{
1. Departamento de Andrologia do Hospital Universitário Professor Edgard Santos da Universidade Federal da Bahia, Salvador, BA. 2. Faculdade de Medicina da Universidade Federal da Bahia, Salvador, BA. 3. Hospital Universitário Professor Edgard Santos da Universidade Federal da Bahia, Salvador, BA.

Endereço para correspodência: Dr. Eduardo J.A. Lopes. R. Altino Seberto de Barros 241, Ed. Memorial Itaigara, Salas 405/406, 41850-010 Salvador, BA, Brasil. Telefax: $55713351-7424$

e-mail: ejalopes@terra.com.br; http://www.eduardolopes.med.br

Recebido para publicação em 21/3/2005

Aceito em 24/3/2006
} 


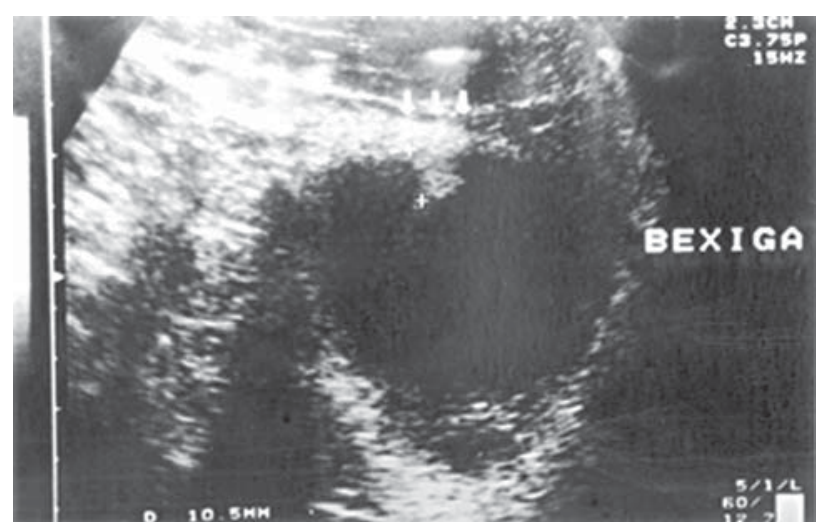

Figura 1 - Ultra-sonografia de projeção de tumor da parede anterior da bexiga.

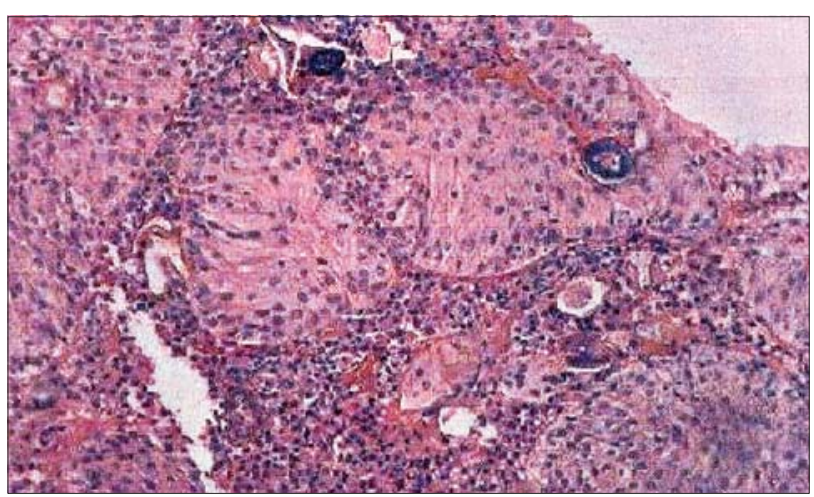

Figura 2 - Hiperplasia de mucosa transicional.

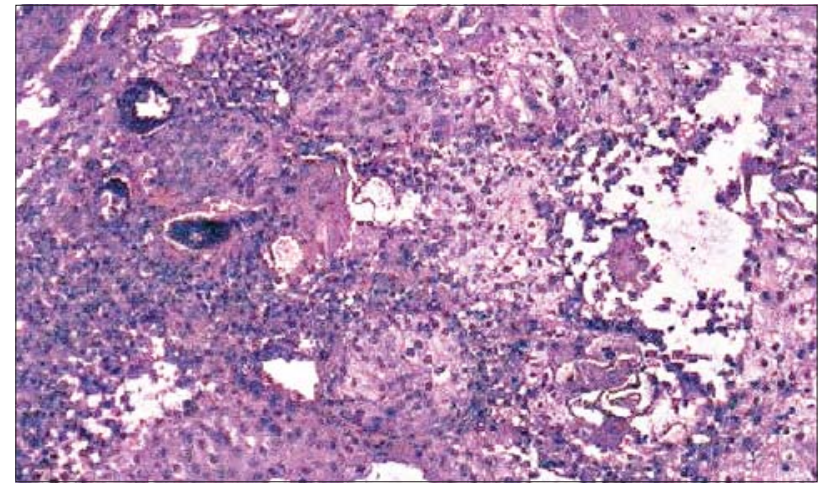

Figura 3 - Foto mostrando vários ovos de S. mansoni no cório.

\section{DISCUSSÃo}

A esquistossomose vesical é rara em nosso meio ${ }^{12}$ e somente três casos foram relatados sendo dois in vivo, ambos tendo apresentado a doença como lesão pseudoneoplasica. Os autores sugerem acompanhamento clínico do paciente até que mais estudos sejam capazes de demonstrar a inexistência de uma possível associação entre esquistossomose mansônica e carcinoma vesical.

\section{REFERÊNCIAS BIBLIOGRÁFICAS}

1. Mitre A, Alfer Jr W, Nahas W, Arap S. Esquistossomose mansônica vesical simulando tumor: Relato de um caso. Revista da Associação Médica Brasileira 26: 74-76, 1980.

2. Sayão R, Cury J, Carneiro Neto Jl. Esquistossomose mansônica vesical. Jornal Brasileiro de Urologia 3: 114-116, 1977. 